\title{
A narrative review of oligometastatic prostate cancer-an evolving paradigm
}

\author{
Kobika Sritharan ${ }^{1,2 \#} \wedge$, Romelie Rieu ${ }^{1 \#}$, Alison Tree ${ }^{1,2}$ \\ ${ }^{1}$ Department of Clinical Oncology, Royal Marsden Hospital NHS Foundation Trust, Surrey, UK; ${ }^{2}$ Institute of Cancer Research, Surrey, UK \\ Contributions: (I) Conception and design: All authors; (II) Administrative support: None; (III) Provision of study materials or patients: None; (IV) \\ Collection and assembly of data: All authors; (V) Data analysis and interpretation: None; (VI) Manuscript writing: All authors; (VII) Final approval of \\ manuscript: All authors. \\ \#These authors contributed equally to this work. \\ Correspondence to: Kobika Sritharan. Academic Urology Unit, Royal Marsden Hospital, Downs Road, Sutton, SM2 5PT, UK. \\ Email: kobika.sritharan@icr.ac.uk.
}

\begin{abstract}
There has been growing interest in oligometastatic prostate cancer (OMPC) with a mounting body of evidence to suggest that it is a distinct disease state, both biologically and prognostically, when compared to polymetastatic prostate cancer. Three subgroups have been recognised; de novo synchronous, metachronous/oligorecurrent and oligoprogressive disease. The belief that patients with OMPC can be treated more aggressively to improve survival is transforming patient care. Identifying these patients poses the first challenge, and we explore the imaging modalities currently utilised and those that are promising. For patients with de novo synchronous OMPC, both early systemic treatment in addition to androgen deprivation therapy (ADT) and radiotherapy to the prostate increase overall survival (OS), and both are increasingly being integrated into routine clinical practice. Metastasis-directed therapy (MDT) has predominantly been delivered using stereotactic body radiotherapy (SBRT) in prostate cancer and studies have shown SBRT is well-tolerated, provides excellent local control and can be used to delay ADT in the metachronous setting. We discuss the current management strategies in OMPC, review the evidence supporting the use of SBRT and outline ongoing trials.
\end{abstract}

Keywords: Oligometastases; synchronous; metachronous; oligorecurrent; stereotactic body radiotherapy (SBRT)

Submitted Jun 04, 2020. Accepted for publication Feb 19, 2021.

doi: 10.21037/apm-20-1215

View this article at: http://dx.doi.org/10.21037/apm-20-1215

\section{Introduction}

Metastatic prostate cancer has conventionally been managed with chemo-hormonal treatment only; the cornerstone of treatment being with luteinizing hormone-releasing hormone (LHRH) analogues, followed by the addition of systemic treatments in a sequential manner. Radium is available for those with bony metastatic disease. The role for local therapy has, until recently, only been for palliation of symptoms. There have been many advances in the diagnosis and management of this group of patients in the last 5 years, but despite this, prostate cancer remains the second most common cause of cancer-related death in men (1).

There has been a shift in the metastatic paradigm as our understanding of the disease process has evolved. The traditional belief is that localised tumours are curable and metastatic spread is incurable, leading ultimately to a shortened life. The concept of oligometastatic spread of cancer has gained traction in recent years in the field of prostate cancer, with over $90 \%$ of international experts at the Advanced Prostate Cancer Consensus Conference

^ORCID: 0000-0001-5632-1282. 
Table 1 Subgroups of oligometastatic disease in prostate cancer

De novo synchronous disease-patients present with limited lesions at the same time as the primary cancer. Hormone sensitive

Metachronous/oligorecurrent disease - patients present following treatment of the primary cancer with limited lesions, when the primary disease remains controlled. Usually hormone sensitive, may have commenced hormonal treatment in the case of biochemical failure and become castrate resistant, but remain oligorecurrent

Oligoprogressive disease - progression of a limited number of metastatic lesions, on a background of well-controlled disease, whilst on systemic treatment. Patients may have, or have had, polymetastatic disease. Evidence for SBRT is lacking in this group (13). Usually hormone resistant

(APCCC) 2019 believing such a clinical picture exists (2).

The 'oligometastatic state' was first defined in 1995 by Hellman and Weichselbaum (3). This was described as an intermediate state that exists along a continuum between localised and widespread metastatic disease, where full polymetastatic potential has not yet been reached. We present the following article in accordance with the Narrative Review reporting checklist (available at http:// dx.doi.org/10.21037/apm-20-1215).

\section{Defining oligometastatic disease}

Despite increasing acknowledgement of this oligometastatic state in prostate cancer, as evidenced by the growing number of studies in this area, there remains no consensus on its definition $(2,4)$. Frequently the definition relies on the number of macroscopic metastases identified; varying from $1-10$ in the literature (5-8) and can be defined on an array of different imaging techniques with their own spectrum of sensitivities. A limited number of lesions, usually $\leq 3-5$, localised to no more than three organs is widely considered as an acceptable definition for oligometastatic disease (9). Size and location of the metastasis can reflect the underlying disease biology and can be pivotal in determining appropriate technique for metastasis-directed therapy (MDT). For example, some studies exclude visceral metastases as they are rarer in prostate cancer, associated with a poorer prognosis, and at risk of higher toxicity with MDT (10).

Patients with oligometastatic disease can be categorised into three distinct groups; de novo synchronous, metachronous or oligorecurrent disease and oligoprogressive disease $(11,12)$ (Table 1).

Metachronous oligometastases, or oligorecurrence, occur in prostate cancer patients at least 3-6 months after completing treatment with curative intent. The delay in presentation in itself defines a relatively good prognosis patient cohort, compared to de-novo metastatic disease. Typically, such cancers have an indolent course associated with an appreciable 5 -year survival even without aggressive local therapies $(14,15)$. Improvements in surveillance with high sensitivity prostate-specific antigen (PSA), imaging and patient engagement has improved early detection of oligorecurrent disease, amenable to targeted therapies.

Synchronous oligometastases constitute a smaller group of men, and exhibit a more aggressive phenotype, as evidenced by a worse prognosis (16). This is perhaps not surprising as the presence of the primary cancer may act as an active source for ongoing metastatic seeding as well as tumour self-seeding (17). This may also be partly due to underestimation of disease at diagnosis with conventional imaging, thus in reality the existence of a more widespread disease in some patients.

The management of oligometastatic disease in prostate cancer is undergoing rapid evolution and, in this article, we describe the current imaging and management strategies for this group of diseases and provide a critical appraisal of the evidence supporting the use of stereotactic body radiotherapy (SBRT).

\section{Selecting patients for ablative treatment}

\section{Genetic biomarkers}

Our understanding of the complex processes that occur at a molecular level during progression from localised tumour to polymetastatic disease in any cancer remains limited. There are two schools of thought. Analysis of micro-RNA (mRNA) levels in samples from both oligo- and polymetastatic patients demonstrate differential mRNA expression profiles indicating that the two are separate diseases biologically and arise from different tumour clones. Interestingly, an upregulation of many mRNAs with tumour suppressive functions were seen in the oligometastatic samples $(18,19)$. 
An alternative theory is that the oligometastatic state lends itself to 'self-seed' further metastases to other sites within the body and thus eventually leading to a polymetastatic state (20).

MicroRNAs, and other molecular markers, play an important role in metastatic disease progression. Identifying and understanding their potential diagnostic and/or prognostic role, although fraught with challenges, may revolutionise the way we manage this group of cancers $(21,22)$.

\section{Radiological staging}

The current choice of imaging modality for identifying an oligometastatic state in prostate cancer is not yet standardised. Conventional imaging techniques, which include computed tomography (CT), magnetic resonance imaging (MRI) and $99 \mathrm{~m}$-technetium methylene diphosphonate ( $\left.{ }^{99 \mathrm{~m}} \mathrm{Tc}-\mathrm{MDP}\right)$ bone scintigraphy, have limitations and frequently underestimate the extent of disease in prostate cancer (23), despite being recommended in standard guidelines (24).

As most lymph node metastases do not meet the RECIST size criteria, the sensitivity of CT and MRI for correctly identifying lymph node disease is low $(25,26)$. Bone scans have a reported 'true' sensitivity of around 65\% for identifying skeletal metastases, when using PET-CT and WB-MRI imaging as comparators $(27,28)$. At the APCCC $2019,79 \%$ of panelists voted that standard imaging was insufficient to define an oligometastatic disease state (2) and it is likely that PSMA-PET scans will be recommended for primary staging in the near future.

The precision of an imaging modality is dependent on what it is measured against. When there is no recognised gold standard with which we can compare it to and histological correlation is not possible, there will be uncertainty about the 'true' accuracy of said imaging technique.

The development of functional and molecular imaging with novel PET radiotracers, some of which target the cancer cells directly, offer a more sensitive approach for the identification of oligometastatic disease especially when combined with anatomical imaging, i.e., a CT or MRI (29). These are outlined in Table 2. Although ${ }^{18} \mathrm{~F}$-FDG-PET is used in many cancers, it has very little value in the staging of prostate cancer due to the low glycolytic activity of prostate cancer cells (53). Choline PET scans however, are useful in evaluating disease recurrence with a reported sensitivity and specificity of greater than $85 \%$ (54), although the sensitivity falls considerably in patients with a low PSA value (49). Its strength lies in the detection of metastatic bony lesions, as it is prone to false positives when assessing lymph nodes. 18-F fluciclovine (Axumin), approved by the FDA in 2016, has become increasingly popular for the detection of recurrence following radical treatment (55). It can detect both bony and soft tissue disease with detection rates increasing with rising PSA values; one study demonstrated a $100 \%$ negative predictive value with a PSA value of greater than $1.05 \mathrm{ng} / \mathrm{mL}$ (56).

Thus far, PSMA PET-CT stands out as the most useful imaging technique overall, even at low PSA levels (57). One study reported a $54 \%$ detection rate of oligometastatic disease on PSMA PET scans in a group of patients who had negative conventional imaging despite rising PSA levels $(<1.0 \mathrm{ng} / \mathrm{mL})$ following radical prostatectomy (58). PSMA PET scans are increasingly playing a role in detecting disease when there is biochemical relapse following radical treatment of the primary cancer, and its use in this setting has been recommended in international guidelines $(2,24)$.

Whole body-MRI (WB-MRI) with the addition of diffusion weight imaging has a lower reported accuracy compared to PSMA PET-CT in the identification of bone metastases and lymph nodes (48). Although, when compared to PSMA PET-CT in the setting of biochemical relapse, WB-MRI is inferior (48) it may be of benefit in assessing response and identifying oligoprogressing lesions (59). The evidence supporting the use of WB-MRI is in its infancy but appears promising.

\section{Current standard of care (SOC)}

\section{Systemic therapies}

For patients who present with newly diagnosed hormone sensitive metastatic prostate cancer (mHSPC), the mainstay of treatment is androgen deprivation therapy (ADT) which is continued lifelong (60). In recent years, large phase 3 randomised trials have demonstrated the survival benefit of adding upfront systemic therapy to ADT.

The phase III study CHAARTED reported an overall survival (OS) benefit in men with $\mathrm{mHSPC}$ with the addition of 6 cycles of docetaxel to SOC ADT at the start of their treatment. The median survival with combination treatment increased significantly; survival in the ADT alone group was 44 months compared to 57.6 months in the ADT and docetaxel group (HR 0.61, 95\% CI, 0.47$0.8, \mathrm{P}<0.001)$. This trial demonstrated an OS benefit in patients with high volume disease (51.2 versus 34.4 months 
Table 2 Imaging modalities available and utilised in metastatic prostate cancer (30-33)

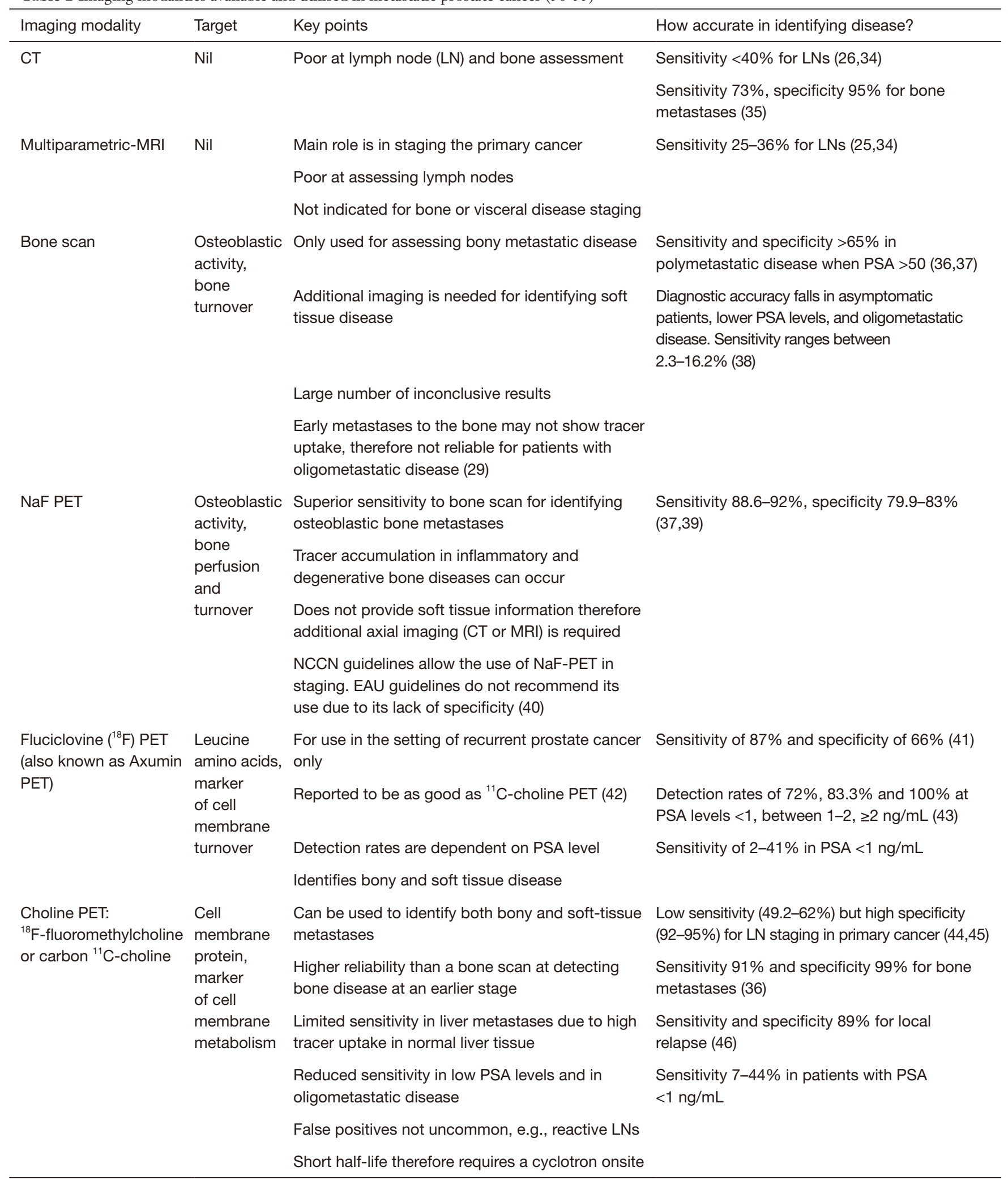

Table 2 (continued) 
Table 2 (continued)

\begin{tabular}{|c|c|c|c|}
\hline Imaging modality & Target & Key points & How accurate in identifying disease? \\
\hline \multirow{2}{*}{$\begin{array}{l}{ }^{68} \text { Ga-PSMA PET- } \\
\text { CT prostate-specific } \\
\text { membrane antigen }\end{array}$} & \multirow{2}{*}{$\begin{array}{l}\text { PSMA } \\
\text { protein, } \\
\text { found in } \\
\text { prostate } \\
\text { cancer cells }\end{array}$} & $\begin{array}{l}\text { High specificity for prostate cancer as PSMA } \\
\text { protein upregulated in prostate cancer cells }\end{array}$ & $\begin{array}{l}\text { Minimal data in literature for bony disease as } \\
\text { gold standard does not exist }\end{array}$ \\
\hline & & $\begin{array}{l}\text { Able to identify smaller lesions at lower PSA } \\
\text { values and therefore ideal for oligometastatic } \\
\text { disease (49) }\end{array}$ & \\
\hline \multirow[t]{4}{*}{$\begin{array}{l}\text { WB-MRI + diffusion } \\
\text { weighted images }\end{array}$} & \multirow[t]{4}{*}{ Nil } & Does not require intravenous contrast injection & $\begin{array}{l}\text { Sensitivity and specificity }>98 \% \text { combine for all } \\
\text { sites }\left({ }^{18} \mathrm{~F} \text { choline PET used as comparator) (50) }\right.\end{array}$ \\
\hline & & $\begin{array}{l}\text { Outperforms conventional imaging in primary } \\
\text { staging (50) }\end{array}$ & \\
\hline & & $\begin{array}{l}\text { One study showed poorer diagnostic accuracy } \\
\text { when compared with PSMA-PET in biochemical } \\
\text { recurrence with a low PSA (48) }\end{array}$ & \\
\hline & & $\begin{array}{l}\text { Not widely utilised at present. There is increasing } \\
\text { evidence to support its use in assessing disease } \\
\text { response especially in bony metastases }(51,52)\end{array}$ & \\
\hline
\end{tabular}

CT, computed tomography; EAU, European Association of Urology; LN, lymph node; MRI, magnetic resonance imaging; NaF, sodium fluoride; NCCN, National Comprehensive Cancer Network; PSA, prostate-specific antigen test; PSMA, prostate-specific membrane antigen; PET, positron emission tomography; WB-MRI, whole-body magnetic resonance imaging.

for $\mathrm{ADT}$ alone, $\mathrm{P}<0.001)$, but not in the low volume group. High volume disease was defined as the presence of visceral metastases or $\geq 4$ bony metastases (with $\geq 1$ bony metastasis outside the spine or pelvis) $(61,62)$. Analysis of the STAMPEDE trial's Arm C data also reported an OS benefit of 10 months in the ADT and docetaxel arm (HR $0.78,95 \% \mathrm{CI}, 0.66-0.93, \mathrm{P}=0.006$ ) (63) but contrariwise, this beneficial effect was seen for all patients, irrespective of disease volume. So, after these publications, the consensus amongst most clinicians, was to offer patients with de novo synchronous oligometastatic prostate cancer (OMPC) early docetaxel alongside ADT regardless of volume of disease (2).

Amongst the mHSPC population, there are two groups; those who present with de novo synchronous metastases, and those who present with metachronous metastases following prior radical treatment to the primary. Published data suggests that those who relapse following prior treatment have better outcomes and therefore benefit less from docetaxel than those with de novo metastatic disease (16).

There is also level 1 evidence that novel androgen receptor targeted therapy also improves OS in newly diagnosed metastatic disease; abiraterone in STAMPEDE (64) and LATITUDE (65), enzalutamide in ENZAMET (66) and apalutamide in TITAN (67). The final analysis of the LATITUDE study demonstrated a significant improvement in OS with the addition of abiraterone and prednisone with ADT (53.3 versus 36.5 months, HR: 0.66 , 95\% CI, 0.56-0.78; $\mathrm{P}<0.0001)$. Within STAMPEDE, patients who received abiraterone and prednisolone with $\mathrm{ADT}$ showed a significantly improved OS (HR 0.66, 95\% CI, 0.44-0.98) and failure free survival (FFS). A post-hoc analysis of the data from the STAMPEDE patients, disease showed a similar benefit regardless of disease volume (68). 
Treatment of the primary cancer: what is the evidence?

Patients who present with low volume de novo synchronous metastatic disease are offered, in addition to ADT and systemic treatment, treatment with radiotherapy to the primary prostate cancer. A number of retrospective trials suggested benefit, but practice did not change until the results of the Phase III STAMPEDE trial (69).

The HORRAD trial, a multicentre randomised study, investigated the impact of adding radiotherapy to the primary cancer in addition to ADT for newly diagnosed mHSPC patients (70); 432 patients were randomised to either ADT alone or ADT and radiotherapy to the primary with a dose of 70 Gy in 35 fractions over 7 weeks or 57.76 Gy in 19 fractions over 6 weeks. This study failed to show a survival benefit in the radiotherapy group, but it was noted that a high proportion of the study patients had a high burden of disease. An unplanned subgroup analysis demonstrated an OS benefit in patients with a lower burden of disease. The STAMPEDE trial investigated the same question but before analysing the data, in response to the HORRAD results, planned a subgroup analysis of low volume versus high volume disease (69). Local prostate radiotherapy with a dose of $55 \mathrm{~Gy}$ in 20 fractions over 4 weeks or 36 Gy in 6 fractions over 6 weeks in combination with standard treatment was compared to SOC alone (ADT +/- early docetaxel). An improvement in FFS (HR 0.76, 95\% CI, 0.68-0.84) was seen but there was no significant benefit in OS or progression free survival (PFS) in the radiotherapy group. Analysis of pre-defined subgroups, as per the CHAARTED trial high volume versus low volume criteria, demonstrated a significant improvement in OS and FFS in the men with low volume disease who received radiotherapy whereas those with a high disease burden did not benefit.

The data from the two studies were pooled into a metaanalysis, STOPCAP, and a 7\% improvement in 3-year survival in men with less than 5 bone metastases was reported (71). A low volume of disease is both prognostic and predictive for the benefit of radiotherapy (72) and therefore radiotherapy to the primary plays an important role in the management of de novo synchronous oligometastatic setting.

\section{MDT in oligometastatic disease}

The concept of treating a limited number of metastases with MDT has been recognised in other tumours and is associated with long-term control, improvement in survival and in some cases, cure (73-75). MDTs can take a variety of forms; radiofrequency ablation (RFA), cryotherapy, surgery and SBRT, and is given with the intent of ablating the lesion. Surgery has a role to play in OMPC, specifically salvage lymphadenectomy but aside from this, most of the evidence, and therefore the justification, for treating prostate cancer oligometastases is with the use of SBRT. In addition, SBRT has many advantages over surgery and other invasive ablative modalities, including lack of need for an anaesthetic, more lesions accessible to SBRT, less side effects and potentially more cost effective too.

Theoretically MDT, using SBRT to ablate all macroscopic disease, will not only achieve local control but will, like treating the primary cancer in low-volume oligometastatic disease, have a similar effect on the disease's natural history; delaying progression and the development of castrate resistant cancer, postponing the need for systemic therapy (and avoiding the associated side effects), and potentially providing long-term disease-free survival.

\section{Radiobiology}

Stereotactic radiotherapy is a method of extreme hypofractionation with external beam radiotherapy (EBRT), in which an ablative radiotherapy dose is delivered with high precision over a maximum of 8 fractions, such that the doseper-fraction is greater than $5 \mathrm{~Gy}$.

The alpha/beta $(\alpha / \beta)$ ratio, derived from the linearquadratic equation, describes the sensitivity of tissue to radiation fraction size (76). The $\alpha / \beta$ ratio of prostate adenocarcinoma, as estimated by hypofractionation trials, is between 1.2-2.7 Gy, whereas early (acute) and late normal tissue reactions have $\alpha / \beta$ ratios, of 10 Gy and 3-5 Gy respectively $(77,78)$. This difference, particularly appreciable in prostate cancer, can be exploited to optimise the ratio between tumour control probability and normal tissue complication probability. Whether our understanding of radiobiology learned from EBRT is directly transferrable to SBRT is unclear. There is potentially some novel cell kill mechanisms, pertaining specifically to extreme hypofractionation treatments, such as tumour vascular disruption or increased anti-tumour immune reactivity (79).

In prostate cancer studies, a variety of dose-fractionation schedules have been used with biological equivalent doses (BED) ranging from 61 to 495; details of selected studies reported in this paper are given in Table 3. Higher BED is 
Table 3 Variability in radiotherapy schedules and trial methodology of selected published trials

\begin{tabular}{|c|c|c|c|c|c|}
\hline $\begin{array}{l}\text { Trial ( } n=\text { number of patients } \\
\text { enrolled) }\end{array}$ & $\begin{array}{c}\text { Total dose/number of } \\
\text { fractions }\end{array}$ & $\begin{array}{c}\text { BED (Gy) } \\
(\alpha / \beta=1.5 \text { used })\end{array}$ & Median F/U & Primary endpoint & $\begin{array}{c}\text { Number of } \\
\text { metastatic lesions } \\
\text { allowed }\end{array}$ \\
\hline $\begin{array}{l}\text { POPSTAR (83), } n=33 \text {, } \\
\text { prospective single arm }\end{array}$ & 20 Gy in $1 \#$ & 286.7 & 2 years & Safety and feasibility & $\leq 3$ \\
\hline $\begin{array}{l}\text { Bouman-Wammes et al. (85), } \\
n=43 \text {, prospective single arm }\end{array}$ & $\begin{array}{c}30 \text { Gy in } 3 \# ; 35 \text { Gy in } 7 \# ; \\
45 \text { Gy in 3\# }\end{array}$ & $230 ; 151.7 ; 495$ & 2.6 years & ADT free survival & $\leq 5$ \\
\hline
\end{tabular}

ADT, androgen deprivation therapy; BED, biologically equivalent dose; F/U, follow-up; OS, overall survival; PD, progressive disease; RCT, randomised controlled trial; \#, fractions of radiotherapy; $\mathrm{PsC}$, prostate cancer.

associated with a higher rate of local control, and several cutoffs have been suggested to ensure tumour ablation for prostate cancer: BED >100 (86), BED >108 (87), and BED >200 (88).

Dose is prescribed to the $50-80 \%$ isodose, ensuring good coverage of the PTV and sharp dose fall away in normal tissues (Figure 1). Reproducibility and accuracy are essential and require modern immobilisation and daily online imaging for verification. Margins depend on the site of disease and an institution's particular set-up error but are generally $2-5 \mathrm{~mm}$. Treatments are typically delivered $>48$ and $<96 \mathrm{~h}$ apart to minimise toxicity, although some institutions treat daily. Given the high BED delivered, some metastases are not suitable for treatment with SBRT; metastases abutting critical structure such as the spinal cord, those located in the "no fly zone" in the pulmonary hilar region, or large tumours where organs at risk prevent adequate dose distribution. In those situations, other MDT techniques such as conventional fractionated radiotherapy, surgery, RFA, microwave ablation or cryotherapy should be considered.

\section{Use of SBRT in oligometastatic disease}

A multi-national survey of over 1,000 oncologists reported that over $60 \%$ of responders recommended SBRT for oligometastases and two-thirds planned to increase this practice (90). This doctor "belief", alongside the appeal of delaying systemic therapy, and the improved access and availability of techniques has led to increasing worldwide SBRT use. However, some argue that standard practise is overtaking the current level of evidence, with reliance on small studies which are vulnerable to bias and have poor controls and inadequate endpoints. The attempts to ablate all sites of disease in metastatic prostate cancer as they arise has been likened to the futility of catching all Pokemon (91), although this was rebutted (92).

\section{Early data}

Early data mainly consists of small single-arm case series. The heterogeneous dose/fractionation schedules, inconsistent use of ADT, widespread dependence on conventional imaging and short follow-up complicate interpretation. This notwithstanding, a systematic review of 661 patients reported median PFS and ADT-free survival of between 1-3 years, excellent local control of $100 \%$ for tumours receiving a BED >108 Gy $(\alpha / \beta=3)$, and importantly, only 1 patient reported grade 3 acute toxicity (87). 


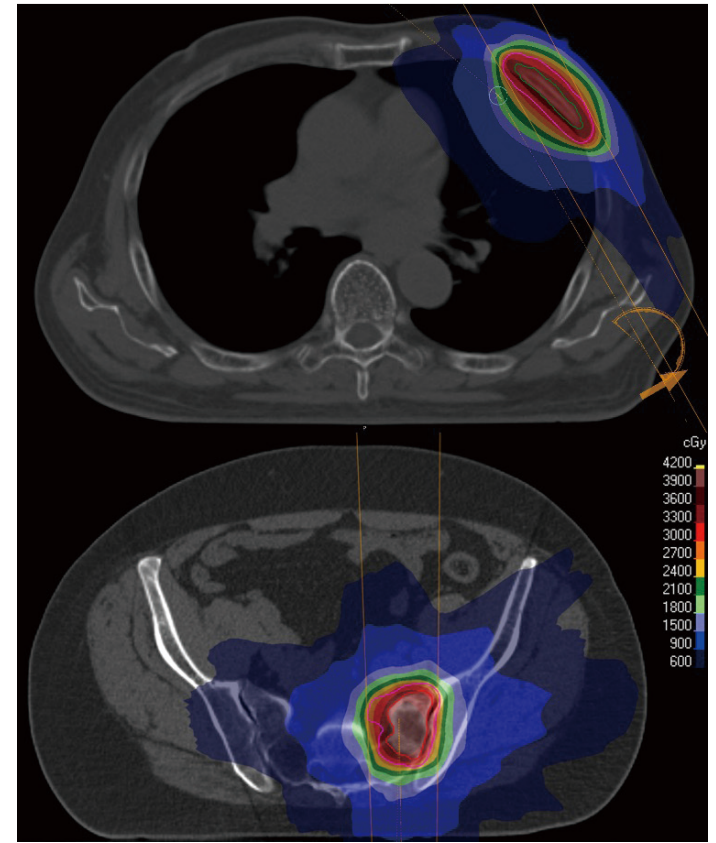

Figure 1 Two SBRT plans for patients with oligoprogressing metastatic lesions treated with $30 \mathrm{~Gy}$ in 5 fractions (BED of $150 \mathrm{~Gy}, \alpha / \beta$ of 1.5$)$ at our institution. Both patients are enrolled in the TRAP trial (NCT 03644303). The axial slice through the chest (top image) demonstrates a rib lesion being treated; the pink line displays the planning target volume (PTV) and the green line is the internal target volume (ITV), contoured on 4D CT, to account for respiratory motion. The axial image through the pelvis (bottom image) demonstrates a sacral lesion being treated; here, the pink line is the PTV and the red line is the gross tumour volume (GTV). Note the 2019 sacral consensus contouring guidelines (89) are not followed here, as total ablation of all disease is not the objective in oligoprogressive disease. There is tight conformity of the prescription dose to the PTV with a rapid dose fall off, minimising dose to surrounding tissues. The orange arrow indicating beam entry.

\section{Data supporting SBRT in metachronous oligometastatic disease}

Accordant results were achieved in the POPSTAR trial, which evaluated the role of SBRT (20 Gy in 1 fraction) to up to 3 bone-only ( $n=20)$, node-only $(n=12)$ or both $(n=1)$ oligometastases (83). Local control was again superb, 2-year local PFS of $93 \%$ (95\% CI, 84-100\%), and although $67 \%$ suffered grade 1-2 side effects, grade 3 reactions were limited to 1 patient (vertebral fracture requiring spinal instrumentation). Distant progression was common [2-year distant PFS 39\% (95\% CI, 25-60\%)] but biased by whether patients were already on $\mathrm{ADT}(\mathrm{n}=11)$; if not, 2-year freedom from $\mathrm{ADT}$ was $48 \%$. A quarter of relapses were amenable to salvage SBRT. Interestingly, three quarters of patients recurring following SBRT to bone-only disease reoccurred in bone, whilst irradiated nodal disease re-occurred only in other nodes. This predilection for recurrence locations manifests the interaction between cancer biology and its microenvironment, a concept described as seed and soil (93). A recent retrospective study of prophylactic nodal treatment found that elective nodal radiotherapy $+/-$ boost, reduces nodal recurrences compared to SBRT $(\mathrm{P}<0.001)$, and for patients with a single node this led to a significantly longer metastases-free survival ( $\mathrm{P}=0.009$; HR $0.5,95 \% \mathrm{CI}$, 0.3-0.85) (94). The current phase II STORM trial (NCT 03569241) (95), is comparing the addition of whole pelvic radiotherapy to SBRT in patients with pelvic nodal disease (see Table 4).

The first randomised phase II trial of SBRT for oligometastases was the STOMP trial, published in December 2017 (81). Over 3 years, this study enrolled 62 patients with a maximum of 3 asymptomatic extracranial choline-PET/CT avid oligometastases. Randomisation between PSA surveillance and MDT, either surgery $(n=6)$ or SBRT $(n=25)$, was stratified by PSA doubling time ( $\leq 3$ versus $>3$ months) and location of metastases (nodal versus non-nodal).

The primary endpoint was ADT-free survival, but the authors minimised its subjectivity by providing clear indications for $\mathrm{ADT}$ : symptomatic progression, progression to more than 3 metastases, or local progression of known metastases. Repeat MDT was permitted if there were three or fewer new metastases $(n=13)$. SBRT was very well tolerated; $17 \%$ of patients reported Grade 1 acute side effects and there was no grade 2 or higher toxicity.

After a median follow-up of 3 years, ADT-free survival was 13 months in the surveillance arm versus 21 months following MDT; HR 0.6 (80\% CI, 0.40-0.9), log-rank $\mathrm{P}=0.11$. Double the number of people in the surveillance arm had to start ADT (12 versus 6). No patient receiving MDT suffered symptomatic progression or local progression, suggesting effective local control. The risk of polymetastatic disease was similar in both arms.

One point of controversy is whether to use SBRT as a method of delaying ADT (as done in STOMP) or to add ADT to SBRT in men who, for the most part, will be on continuous androgen suppression for life thereafter. In a purely palliative setting, delaying ADT and avoiding side-effects is hugely attractive, echoing the principle "first do no harm". Conversely, the TOAD trial showed benefit to immediate 
Table 4 Selected trials in metachronous and synchronous metastases (prostate only trials except where noted in the first column)

\begin{tabular}{l}
\hline Trial \\
\hline Metachronous metastases \\
only \\
CORE (96), phase II \\
RCT, UK/Australia, NCT \\
02759783, Recruitment \\
complete, $\mathrm{n}=245$, prostate, \\
lung or breast cancer \\
SABR-COMET 3 (97), phase \\
III RCT, Canada/UK, NCT \\
03862911, Recruitment \\
started Nov 2019, aim: \\
$\mathrm{n}=297$, various tumour \\
types
\end{tabular}

SABR-COMET 10 (98), phase II, Canada, NCT 03721341, Recruitment started February 2019, aim: $n=159$, various tumour types

Study comparison + primary endpoint

Key criteria
(1:1) SOC versus SOC + SBRT. SOC is at the discretion of the local oncologist. SBRT dose/fractionation dependent on metastatic site and proximity to normal tissues. Primary endpoint: PFS

(1:2) SOC versus SOC + SBRT. SOC = hormones +/or chemotherapy +/or palliative radiotherapy (8 Gy in 1\#, 20 Gy in 5\#, 30 Gy in 10\#) at discretion of oncologist. $\mathrm{SBRT}=$ recommended schedules provided depending on site and size of metastases. Primary endpoint: OS
(1:2) SOC versus SOC + SBRT. SOC = chemotherapy, immunotherapy, hormones, radiotherapy or observation at discretion of oncologist. Palliative radiotherapy doses include: 8 Gy in 1\#, 20 Gy in 5\#, 30 Gy in 10\#. $\mathrm{SBRT}=$ recommended schedules 20Gy in 1\#; 30 Gy in 3\# (every 2 days), or 35 Gy in 5\# (daily). Primary $\leq 3$ extracranial metachronous oligometastatic lesions. A maximum of 2 different organs may contain metastases (can include visceral disease). Hormone resistant prostate cancer included. PET or WBDWMRI preferred but not mandated

$\leq 3$ metachronous oligometastatic lesions. Maximum size $6 \mathrm{~cm}$ (unless in bone and can be safely treated) or $3 \mathrm{~cm} / 30 \mathrm{cc}$ in brain.

Randomisation stratified by: A) Histology: Group 1: prostate, breast or renal; Group 2: others. B) Disease-free interval: $\leq 2$ years versus $>2$ years. Biopsy of metastases preferred; must include PET-CT or NM bone scan endpoint: OS (timeframe 6 years)

(1:1) MDT (sLND or SBRT) versus MDT + whole pelvic radiotherapy. 6 months of ADT is given in BOTH arms. Primary endpoint: metastases-free survival (time frame 2 years)

started April 2018, 2 years)

aim: $n=178$, estimated

completion: 2023

ARTO (99), phase II, Italy,

(1:1) ADT + abiraterone + prednisolone versus SBRT

NCT 03449719, recruitment + ADT + abiraterone + prednisolone. SBRT = dose/ started May 2018,

aim: $n=174$, estimated

completion: 2022 fractionation depend on size and location of lesions, and normal tissue constraints. BED $>100$ Gy $(\alpha / \beta=3)$ is recommended. Primary endpoint: rate of PSA response

4-10 metachronous oligometastatic lesions: size $<5 \mathrm{~cm}$ (or $<3 \mathrm{~cm} / 30 \mathrm{cc}$ in brain). Excludes metastases in Gl tract, mesenteric LN or skin. Randomisation will be stratified by histology: Group 1: prostate, breast or renal; Group 2: others. Also stratified by type of pre-specified systemic therapy: immunotherapy/targeted versus cytotoxic versus observation. Biopsy of metastases preferred. Diagnostic imaging not specified

$\leq 3$ lymph nodes in pelvis; superior limit at level of aortic bifurcation. Diagnostic imaging must include PSMA or FACBC PET-CT. Excludes local relapse in prostate gland/bed not suitable for curative treatment

$\leq 3$ nodal and/or bone oligometastatic lesions. Only patients with hormone resistant prostate cancer are enrolled. Visceral lesions are excluded. Patients to start on abiraterone/prednisolone for 30 days prior to $\mathrm{RT}$

Metachronous and synchronous metastases

PRESTO (100), phase III RCT, France GETUG-AFU, (1:1) SOC versus SOC + SBRT. SOC = RT to primary cancer (in de novo setting) + ADT. Abiraterone or docetaxel following tumour board meeting. SBRT $=30$ Gy in 3\#. Primary Endpoint: castration resistant prostate cancer free survival

started Dec 2019 , aim: $n=350$, estimated completion: 2027

PLATON trial (101), phase

(1:1) SOC versus SOC + SBRT. Zoladex in both arms. III, Canada, NCT 03784755, SOC = systemic therapy at discretion of oncologist + recruitment started April 2019, aim, $n=410$, estimated completion: 2025 ablative therapy to untreated prostate cancer. SBRT $=$ dose/fractionation not specified. Primary endpoint: failure-free survival (time from randomisation to first occurrence, within 6-year timeframe) $\leq 5$ synchronous or metachronous oligometastatic lesions; including at least 1 bone metastasis (i.e., stage M1). Excludes visceral metastases. Requires functional imaging (F- or C-choline PETCT or PSMA PET-CT or whole-body MRI)

$\leq 5$ metachronous or synchronous metastases. $\leq 3$ metastases in any non-bone organ system. Imaging must include CT- or MRI-chest/abdomen/ pelvis, and NM bone scan

Table 4 (continued) 
Table 4 (continued)

\begin{tabular}{|c|c|c|}
\hline Trial & Study comparison + primary endpoint & Key criteria \\
\hline \multicolumn{3}{|l|}{$\begin{array}{l}\text { Synchronous metastases } \\
\text { only }\end{array}$} \\
\hline $\begin{array}{l}\text { TED trial (103), phase } \\
\text { II, United States, NCT } \\
\text { 02716974, recruitment } \\
\text { started June 2016, aim: } \\
\text { n=26, estimate completion: } \\
2022\end{array}$ & $\begin{array}{l}\text { Single arm. Neoadjuvant LHRHa }+ \text { up to } 6 \text { cycles of } \\
\text { docetaxel. If PSA falls } \geq 50 \% \text { from baseline, RP }+/- \\
\text { adjuvant RT then consolidation SBRT to metastases. } \\
\text { Total androgen deprivation for } 1 \text { year. Primary endpoint: } \\
\text { 2-year PSA progression free }(<0.2 \mathrm{ng} / \mathrm{mL}) \text { survival in } \\
\text { men with non-castrate testosterone levels }\end{array}$ & $\begin{array}{l}\leq 5 \text { de novo synchronous oligometastases. } \\
\text { Patients with visceral disease excluded. Imaging } \\
\text { accepted: bone scan, contrast enhanced CT CAP } \\
\text { or PET scan }\end{array}$ \\
\hline
\end{tabular}

ADT, androgen deprivation therapy; CT CAP, computerised tomography chest, abdomen and pelvis; LN, lymph nodes; NaF, sodium fluoride; NSCLC, non-small cell lung cancer; OS, overall survival; PET, positron emission tomography; PFS, progression free survival; PSMA, prostate specific membrane antigen; RP, radical prostatectomy; RT, radiotherapy; RCT, randomised controlled trial; SOC, standard of care; SBRT, stereotactic body radiotherapy; sLND, salvage lymph node dissection; WBDWMRI, whole-body diffusion-weighted magnetic resonance imaging; \#, fractions of radiotherapy.

ADT with a HR 0.55 (95\% CI, 0.3-1.0; P=0.05) (104) in a largely PSA-only relapsed population. However, over $80 \%$ of patients had side effects on ADT that affected their quality of life scores. Furthermore, the results have not been replicated (105): the EORTC 30891 demonstrated no change in prostate cancer mortality with immediate ADT (106), and other retrospective data has shown significant benefit only in a subgroup of high risk patients with Gleason 7 or a PSA doubling time of less than 12 months but not in the overall group (107). Currently, both immediate and delayed ADT options are included in the EAU-ESTRO-SIGO guidelines on metastatic prostate cancer (108). Intermittent $\mathrm{ADT}$ is an alternative to continuous $\mathrm{ADT}$, with promising toxicity and QOL outcomes. However, direct comparisons between intermittent and continuous ADT have found clinically important survival differences $(109,110)$, and importantly the SWOG trial failed to demonstrate noninferiority. Continuous ADT is therefore recommended except for well-informed, motivated patients who are troubled by side effects, have a reliable PSA response, and undergo increased surveillance.

There is robust evidence that ADT, in combination with primary radiotherapy, or salvage prostate bed radiotherapy, improves survival (111-114). Whilst there is no high quality evidence to answer this question with MDT, data from a pan-European cohort suggested there may be an improvement in PFS if ADT is combined with SBRT (18 versus 25 months, $\mathrm{P}=0.09$ ) (86). Similarly, a recent single-centre, retrospective study of SBRT with either immediate versus delayed ADT, as chosen by patients $(n=88)$, demonstrated a PFS benefit for immediate ADT (26 versus 16 months, $\mathrm{P}<0.007)$ (115). Interestingly, the 2019 APCCC, of which $26 \%$ are radiation specialists, reported an expert consensus that combination ADT and MDT was needed for oligometastatic disease, and the majority of ongoing trials are including concurrent ADT (see Table 4). Questions remain; does concurrent ADT with MDT improve survival in the oligometastatic setting? If so, how long should it be continued, and should other systemic therapies also be considered?

The recently published phase II multicentre randomised trial, ORIOLE, confirms the safety, deliverability and benefit, in terms of delaying ADT, that was shown in STOMP (82). In ORIOLE 54 patients with up to 3 metastases detectable by CT, MRI and/or radionuclide bone scan were randomised 2:1 to either SBRT or observation. The primary endpoint was a composite of outcomes at 6 months including, unlike STOMP, PSA level (increase 25\% above the nadir and at least $2 \mathrm{ng} / \mathrm{dL}$ ) and ADT initiation for any reason, as well as symptomatic progression, progression on conventional imaging and death.

Patients in the observation arm were more likely to 
progress than those receiving SBRT; 61\% versus 19\%, $\mathrm{P}=0.005$. Unlike STOMP, patients undergoing SBRT underwent PSMA PET at baseline and on day 180, however the baseline scans were not used to select for, or plan SBRT. Thus, 16 of the 36 participants receiving SBRT had baseline PSMA PET-avid lesions that were not included in the treatment fields. In subgroup analysis this led to a significant difference in the primary endpoint: 6 of 16 patients partially treated had progressed compared to only 1 of 19 patients that had all PSMA-identified lesion treated $(\mathrm{P}=0.03)$. This highlights the need for sensitive imaging.

To investigate the interaction between MDT and the immune system, ORIOLE sampled peripheral blood at baseline and day 90; sequencing T-cell receptor clonotypes and performing DNA CAPPSeq (cancer personalised profiling by deep sequencing). Whilst no clusters of $\mathrm{T}$ cells were reported at baseline, after SBRT 3 patients had an expanded T-cell receptor cluster; which the authors noted may be an immune response to increased cancer-antigen production. Based on ctDNA only those without high risk mutations had a significant PFS benefit with SBRT. However, the lack of biopsy to match the ctDNA mutations with prostate tumour, and the small numbers involved mean the results are just the first explorative hint of how the baseline immune phenotype and tumour mutation signature may predict clinical response to SBRT.

The strongest evidence of the impact of SBRT on OS is provided by the multi-national phase II trial, SABRCOMET (116). It included 99 patients with various cancers, of which only 16 had prostate cancer. Patients were randomly assigned (1:2) SOC or SOC plus SBRT to up to 5 metastatic lesions, stratified for those with either $1-3$, or 4-5 metastases. There was a $10 \%$ excess of patients with solitary metastases in the SBRT group (46\% versus 36\%), whereas only 7 people overall had 4-5 metastases. Primary cancer was not stratified for, and 14 of the 16 prostate cancer patients were randomised to receive SBRT. Less than $50 \%$ of patients in each arm underwent a CT-PET scan before enrolment.

After a median follow-up of 25 months, the median OS was increased by 13 months in the SBRT group; 28 versus 41 months (HR 0.57, 95\% CI, 0.3-1.0; $\mathrm{P}=0.026$ ) and there was a doubling of median PFS from 6 to 12 months (HR 0.47, 95\% CI, 0.3-0.76, P=0.0012). Local control with SBRT was $75 \%$ compared to $49 \%$ in the control group $(\mathrm{P}=0.001) .12 \%$ received repeat SBRT on disease progression. There were 3 treatment-related deaths ( $4.5 \%$ treatment-related mortality), including radiation pneumonitis $(\mathrm{n}=1)$, pulmonary abscess $(\mathrm{n}=1)$, and postoperative subdural haemorrhage following repair of an SBRT-related perforated gastric ulcer $(n=1)$. The deaths highlight the need to consider how the tumour location affects the risk/benefit profile of SBRT in our often vulnerable patient cohorts. A contemporary prospective cohort with similar populations, interventions and analysis to SABR-COMET, has shown consistent results, with a median OS of 42 months, local control at 1 year of $91 \%$, and no effect on quality of life (80).

Having reviewed the evidence for clinical effectiveness and safety of SBRT for oligometastatic disease the NHS now commissions SBRT treatment for up to 3 metachronous oligometastatic lesions.

\section{Data in synchronous oligometastatic disease}

Patients who are diagnosed with de novo synchronous oligometastatic will be offered ADT, systemic treatment (docetaxel, abiraterone, enzalutamide or apalutamide are all options) and radiotherapy to the primary cancer. This group of patients have a better prognosis than those who present with polymetastatic disease but a worse prognosis than those with metachronous metastases $(16,117)$.

In the majority of studies exploring MDT with SBRT for OMPC, the proportion of enrolled patients who have synchronous oligometastases is very low. Studies in patients with only synchronous metastatic disease are sparse (118-120). Despite the lack of any prospective data, over half the panelists at the 2019 APCCC conference indicated that in de novo synchronous OMPC patients, they would treat low volume metastatic disease with focal ablative treatment alongside treatment for the primary cancer (2).

O'Shaughnessy et al. demonstrated the feasibility of eliminating detectable disease in patients with de novo synchronous oligometastatic disease at presentation, in a small pilot study consisting of 20 men (118). These men received multimodal treatment with ADT, surgery (radical prostatectomy and lymphadenectomy) followed by SBRT to the metastatic lesions. The primary endpoint, an undetectable PSA after testosterone recovery, was achieved in $20 \%$ (95\% CI, 3-38\%) of the men up to 20 months and persisted to nearly 4 years in one patient. There was no comparator arm.

A small Japanese study ( $\mathrm{n}=40$ ) was published in 2018 . The team assessed the benefit of adding MDT to patients with newly diagnosed OMPC (defined as $\leq 5$ lesions) who underwent high dose rate brachytherapy (HDR-BT) and at least 6 months of ADT (120). A heterogenous group 
of patients were enrolled with N1 (n=22), M1a ( $n=3)$ and M1b ( $n=15)$ disease. 18 patients received MDT and the groups were not matched well; there was a preponderance of nodal disease in the control arm. Patients who received MDT had a significantly higher probably of achieving a PSA level of $<0.02 \mathrm{ng} / \mathrm{mL}$ ( $88.8 \%$ vs. $54.5 \%, \mathrm{P}=0.0354$ ) and also had an improved CRPC-free survival (HR 0.32, 95\% CI, 0.12-0.88) than those who did not receive MDT. Bone metastases were treated using a $3 \mathrm{D}$ conformal technique to a dose of 30-50 Gy in 2 Gy per fraction. For involved pelvis lymph nodes, a whole pelvic EBRT dose to 40 Gy followed by a $10 \mathrm{~Gy}$ boost to the node was delivered in addition to the HDR-BT to the prostate. Treatment was also delivered in 2 Gy per fraction.

If we believe these patients are truly oligometastatic, and thus potentially curable, the question must be asked, should we be treating these patients more aggressively? Should we be considering a 'radical' dose of radiotherapy to the prostate and treating the metastatic lesions with ablative doses (BED >100 Gy) (86). This question will be answered by the forthcoming arm of the STAMPEDE trial, Arm $M$, which will randomise to SOC (including docetaxel or novel androgen receptor targeting agent) +/- radiotherapy to the primary and all known sites of metastatic disease ( $\leq 5$ metastases). This arm is scheduled to open in 2020 .

The 'Total eradication of disease (TED)' trial (NCT 02716974) is currently running at Johns Hopkins Hospital to investigate a similar question. Patients are being treated with neoadjuvant LHRH agonist and docetaxel to 6 cycles followed by radical prostatectomy with or without postoperative radiotherapy and finally, consolidation SBRT to the oligometastases $(103,121,122)$. There are two parts to this trial; TED1 enrolls men with newly diagnosed OMD, and TED2 are for those men diagnosed at the time of surgery, i.e., with positive lymph nodes. Other trials investigating the role of SBRT in synchronous oligometastatic disease are outlined in Table 4.

Patients presenting with synchronous pelvic nodal metastases are a specific subgroup of the oligometastatic group, where clinical consensus is to treat more radically. There is increasing evidence that radical radiotherapy to the prostate and pelvic lymph nodes improves survival outcomes (123) and despite the lack of phase III evidence, guidelines recommend treating the entire pelvic lymph node basin with a boost to the involved lymph nodes (24). The best evidence available arises from a post-hoc exploratory analysis of the control arm in the STAMPEDE trial. A nonrandomised comparison favoured the use of radiotherapy
( $80 \%$ of whom received radiotherapy to the prostate and pelvis) in both high risk node negative and node positive disease (124).

\section{Oligoprogressive disease}

Oligoprogression describes a scenario in which a patient has a limited number of progressing metastatic lesions or a new lesion, on the background of well-controlled systemic disease (13). Patients with oligoprogression have a worse prognosis than those with oligometastases, as they are usually in the hormoneresistant phase of disease. For instance, in a patient with widespread bone disease controlled on ADT, oligoprogression suggests a niche of treatment-resistant cancer cells, ablation of which could theoretically delay widespread treatment resistance and the need to change systemic therapy (125). The volume of controlled disease and the interval to development of oligoprogression are likely to be critical factors determining who will benefit from MDT in this circumstance. As yet there is no prospective randomised data supporting this hypothesis, however, in 2018 the Targeted Radiotherapy in Androgen-suppressed Prostate Cancer Patients (TRAP) phase II, UK-based study started recruiting (NCT 03644303) (126). It is investigating the use of SBRT to 1 or 2 lesions in men receiving a second-generation ADT (abiraterone or enzalutamide). The primary endpoint is median PFS, with estimated study completion at the end of 2021.

\section{Ongoing trials}

Whilst the evidence to date suggests a benefit from SBRT in OMPC, without a large, adequately powered phase III trial, it is impossible to be sure about the existence and magnitude of any benefit. Table 4 outlines selected ongoing trials in metachronous and synchronous metastases.

\section{Future directions}

Thus far, the spotlight in OMD has been on delivering aggressive MDT treatment, to achieve local control, improve survival and potentially, cure. If the results of the current phase III trials are positive, and demonstrate a benefit, our next focus should be refining patient selection. Future research can interrogate the surveillance strategies that recognise and delineate metastases, optimise the radiotherapy protocols, consider concurrent systemic therapies, and importantly incorporate liquid biopsy and biomarkers to stratify patients into risk groups. Well- 
constructed trials are essential if outcomes are to be translated to patient care, the principles of which are discussed in a recent editorial by Chang et al. (127).

The role of immunotherapy in the treatment of oligometastases is covered in detail elsewhere in this edition by Chmura et al. Hitherto, the role of immunotherapy in prostate cancer management has been minimal, probably due in part to the low genetic mutational load and sparsity of activated tumour-infiltrating lymphocytes. However, this is worthy of further study. The phase 2 POSTCARD trial (NCT 03795207) of SBRT for oligometastases with or without durvalumab, a PDL1 inhibitor, is currently recruiting and due for completion in 2024 (128).

Broadening the aims of treatment, an editorial by Palma et al., recently described a possible new approach for MDT, which they called Ablative Radiation Therapy to Restrain Everything Safely Treatable (ARREST). ARREST would aim to temporarily delay tumour progression at multiple tumour sites, recognising inevitable recurrence. Since increasing tumour burden is associated with reduced systemic therapy effectiveness, the authors hypothesise that ARREST could improve systemic therapy itself. Thus, burden of disease would be secondary to feasibility of treatment (129).

\section{Conclusions}

The optimal management for patients with OMPC is multifaceted and there remain many areas where there is lack of good evidence. The efficacious and safe nature of SBRT in ablating oligometastases has been reported in multiple trials. Although data confirms delayed disease progression, prolonged local control, and a suggestion of OS benefit, high quality phase III trials are still needed. With time, we will hopefully be able to ascertain the best approach to manage such a heterogenous group of patients. Until then, we must proceed with pragmatism, and treat patients with the best available evidence, ensuring harm is minimised.

\section{Acknowledgments}

This paper represents independent research supported by the National Institute for Health Research (NIHR) Biomedical Research Centre at The Royal Marsden NHS Foundation Trust and the Institute of Cancer Research, London. The views expressed are those of the authors and not necessarily those of the NIHR or the Department of Health and Social Care. We gratefully acknowledge the support of The Royal Marsden Cancer Charity and Prostate
Cancer UK, who fund the TRAP trial. Funding: None.

\section{Footnote}

Provenance and Peer Review: This article was commissioned by the Guest Editors (Simon Lo, Michael Milano, Tithi Biswas, Charles Simone) for the series "OligometastasisFallacy or Real Deal?" published in Annals of Palliative Medicine. The article has undergone external peer review.

Reporting Checklist: The authors have completed the Narrative Review reporting checklist. Available at http:// dx.doi.org/10.21037/apm-20-1215

Peer Review File: Available at http://dx.doi.org/10.21037/ apm-20-1215

Conflicts of Interest: All authors have completed the ICMJE uniform disclosure form (available at http://dx.doi. org/10.21037/apm-20-1215). The series "OligometastasisFallacy or Real Deal?" was commissioned by the editorial office without any funding or sponsorship. AT reports grants and personal fees from Elekta, grants from Varian, grants from Accuray, personal fees from Janssen, other from Astellas, personal fees from Bayer, personal fees from Ferring, personal fees from Genesis healthcare, outside the submitted work. The authors have no other conflicts of interest to declare.

Ethical Statement: The authors are accountable for all aspects of the work in ensuring that questions related to the accuracy or integrity of any part of the work are appropriately investigated and resolved.

Open Access Statement: This is an Open Access article distributed in accordance with the Creative Commons Attribution-NonCommercial-NoDerivs 4.0 International License (CC BY-NC-ND 4.0), which permits the noncommercial replication and distribution of the article with the strict proviso that no changes or edits are made and the original work is properly cited (including links to both the formal publication through the relevant DOI and the license). See: https://creativecommons.org/licenses/by-nc-nd/4.0/.

\section{References}

1. Prostate cancer statistics I Cancer Research UK [Internet]. 
[cited 2020 May 22]. Available online: https://www. cancerresearchuk.org/health-professional/cancer-statistics/ statistics-by-cancer-type/prostate-cancer\#heading-One

2. Gillessen S, Attard G, Beer TM, et al. Management of Patients with Advanced Prostate Cancer: Report of the Advanced Prostate Cancer Consensus Conference 2019. Eur Urol 2020;77:508-47.

3. Hellman S, Weichselbaum RR. Oligometastases. J Clin Oncol 1995;13:8-10.

4. Saad F, Canil C, Finelli A, et al. Controversial issues in the management of patients with advanced prostate cancer: Results from a Canadian consensus forum. Can Urol Assoc J 2020;14:E137-E149.

5. Lancia A, Zilli T, Achard V, et al. Oligometastatic prostate cancer: The game is afoot. Cancer Treat Rev 2019;73:84-90.

6. Kothari G, Ost P, Cheung P, et al. Trends in Management of Oligometastatic Hormone-Sensitive Prostate Cancer. Curr Oncol Rep 2019;21:43.

7. D'Angelillo RM, Francolini G, Ingrosso G, et al. Consensus statements on ablative radiotherapy for oligometastatic prostate cancer: A position paper of Italian Association of Radiotherapy and Clinical Oncology (AIRO). Crit Rev Oncol Hematol 2019;138:24-8.

8. Khoo V. New concepts in prostate cancer management: the conundrum of managing oligometastatic disease in prostate cancer-through the looking glass darkly. Clin Radiol 2019;74:865-75.

9. Fodor A, Cozzarini C, Fiorino C, et al. Oligometastatic disease in prostate cancer, a continuously changing paradigm: Patient selection and treatment strategy. Transl Cancer Res 2017;6:S112-6.

10. Drake CG. Visceral metastases and prostate cancer treatment: 'Die hard,' 'tough neighborhoods,' or 'evil humors'? Oncology (Williston Park) 2014;28:974-80.

11. Tree AC, Khoo VS, Eeles RA, et al. Stereotactic body radiotherapy for oligometastases. Lancet Oncol 2013;14:e28-37.

12. Niibe Y, Hayakawa K. Oligometastases and oligorecurrence: The new era of cancer therapy. Jpn J Clin Oncol 2010;40:107-11.

13. Patel PH, Palma D, McDonald F, et al. The Dandelion Dilemma Revisited for Oligoprogression: Treat the Whole Lawn or Weed Selectively? Clin Oncol (R Coll Radiol) 2019;31:824-33.

14. De Bruycker A, Lambert B, Claeys T, et al. Prevalence and prognosis of low-volume, oligorecurrent, hormonesensitive prostate cancer amenable to lesion ablative therapy. BJU Int 2017;120:815-21.
15. Sridharan S, Steigler A, Spry NA, et al. Oligometastatic bone disease in prostate cancer patients treated on the TROG 03.04 RADAR trial. Radiother Oncol 2016;121:98-102.

16. Francini E, Gray KP, Xie W, et al. Time of metastatic disease presentation and volume of disease are prognostic for metastatic hormone sensitive prostate cancer (mHSPC). Prostate 2018;78:889-95.

17. Gundem G, Van Loo P, Kremeyer B, et al. The evolutionary history of lethal metastatic prostate cancer. Nature 2015;520:353-7.

18. Uppal A, Ferguson MK, Posner MC, et al. Towards a molecular basis of oligometastatic disease: Potential role of micro-RNAs. Clin Exp Metastasis 2014;31:735-48.

19. Lussier YA, Khodarev NN, Regan K, et al. Oligo- and Polymetastatic Progression in Lung Metastasis(es) Patients Is Associated with Specific MicroRNAs. PLoS One 2012;7:e50141.

20. Chow K, McCoy P, Stuchbery R, et al. Developments in oligometastatic hormone-sensitive prostate cancer. World J Urol 2019;37:2549-55.

21. Korpal M, Ell BJ, Buffa FM, et al. Direct targeting of Sec23a by miR-200s influences cancer cell secretome and promotes metastatic colonization. Nat Med 2011;17:1101-8.

22. Pitroda SP, Khodarev NN, Huang L, et al. Integrated molecular subtyping defines a curable oligometastatic state in colorectal liver metastasis. Nat Commun 2018;9:1793.

23. Thomas L, Balmus C, Ahmadzadehfar H, et al. Assessment of bone metastases in patients with prostate cancera comparison between 99mTC-bone-scintigraphy and [68Ga]Ga-PSMA PET/CT. Pharmaceuticals 2017;10:68.

24. Mottet N, Bellmunt J, Bolla M, et al. EAU-ESTROSIOG Guidelines on Prostate Cancer. Part 1: Screening, Diagnosis, and Local Treatment with Curative Intent. Eur Urol 2017;71:618-29.

25. Wolf JS, Cher M, Dall'Era M, et al. Original Articles: Prostate Cancer: The Use and Accuracy of CrossSectional Imaging and Fine Needle Aspiration Cytology for Detection of Pelvic Lymph Node Metastases Before Radical Prostatectomy. J Urol 1995;153:993-9.

26. Hövels AM, Heesakkers RAM, Adang EM, et al. The diagnostic accuracy of CT and MRI in the staging of pelvic lymph nodes in patients with prostate cancer: a metaanalysis. Clin Radiol 2008;63:387-95.

27. Minamimoto R, Loening A, Jamali M, et al. Prospective comparison of $99 \mathrm{mTc}-\mathrm{MDP}$ scintigraphy, combined $18 \mathrm{~F}-\mathrm{NaF}$ and 18F-FDG PET/CT, and whole-body MRI in patients with breast and prostate cancer. J Nucl Med 2015;56:1862-8. 
28. Cho SY, Szabo Z. Molecular imaging of urogenital diseases. Semin Nucl Med 2014;44:93-109.

29. Joice GA, Rowe SP, Pienta KJ, et al. Oligometastatic Prostate Cancer: Shaping the Definition With Molecular Imaging and an Improved Understanding of Tumor Biology. Curr Opin Urol 2017;27:533-41.

30. Futterer JJ, Surcel C, van den Bergh R, et al. Imaging modalities in synchronous oligometastatic prostate cancer. World J Urol 2019;37:2573-83.

31. Perez-Lopez R, Tunariu N, Padhani AR, et al. Imaging Diagnosis and Follow-up of Advanced Prostate Cancer: Clinical Perspectives and State of the Art. Radiology 2019;292:273-86.

32. Tosoian JJ, Gorin MA, Ross AE, et al. Oligometastatic prostate cancer: Definitions, clinical outcomes, and treatment considerations. Nat Rev Urol 2017;14:15-25.

33. Evans JD, Jethwa KR, Ost P, et al. Prostate cancer-specific PET radiotracers: A review on the clinical utility in recurrent disease. Pract Radiat Oncol 2018;8:28-39.

34. Harisinghani MG, Barentsz J, Hahn PF, et al. Noninvasive Detection of Clinically Occult Lymph-Node Metastases in Prostate Cancer. N Engl J Med 2003;348:2491-9.

35. Yang HL, Liu T, Wang XM, et al. Diagnosis of bone metastases: a meta-analysis comparing 18FDG PET, CT, MRI and bone scintigraphy. Eur Radiol 2011;21:2604-17.

36. Shen G, Deng H, Hu S, et al. Comparison of cholinePET/CT, MRI, SPECT, and bone scintigraphy in the diagnosis of bone metastases in patients with prostate cancer: a meta-analysis. Skeletal Radiol 2014;43:1503-13.

37. Wondergem M, van der Zant FM, Knol RJJ, et al. 99mTcHDP bone scintigraphy and $18 \mathrm{~F}$-sodiumfluoride PET/CT in primary staging of patients with prostate cancer. World J Urol 2018;36:27-34.

38. Abuzallouf S, Dayes I, Lukka H. Baseline staging of newly diagnosed prostate cancer: a summary of the literature. J Urol 2004;171:2122-7.

39. Even-Sapir E, Metser U, Mishani E, et al. The detection of bone metastases in patients with high-risk prostate cancer: 99mTc-MDP Planar bone scintigraphy, singleand multi-field-of-view SPECT, 18F-fluoride PET, and 18F-fluoride PET/CT. J Nucl Med 2006;47:287-97.

40. Wallitt KL, Khan SR, Dubash S, et al. Clinical pet imaging in prostate cancer. Radiographics 2017;37:1512-36.

41. Ren J, Yuan L, Wen G, et al. The value of anti-1-amino-318F-fluorocyclobutane-1-carboxylic acid PET/CT in the diagnosis of recurrent prostate carcinoma: a meta-analysis. Acta Radiol 2016;57:487-93.

42. Nanni C, Zanoni L, Pultrone C, et al. 18F-FACBC (anti1-
amino-3-18F-fluorocyclobutane-1-carboxylic acid) versus 11C-choline PET/CT in prostate cancer relapse: results of a prospective trial. Eur J Nucl Med Mol Imaging 2016;43:1601-10.

43. Akin-Akintayo OO, Jani AB, Odewole O, et al. Change in Salvage Radiotherapy Management Based on Guidance With FACBC (Fluciclovine) PET/CT in Postprostatectomy Recurrent Prostate Cancer. Clin Nucl Med 2017;42:e22-8.

44. Evangelista L, Guttilla A, Zattoni F, et al. Utility of Choline Positron Emission Tomography/Computed Tomography for Lymph Node Involvement Identification in Intermediate- to High-risk Prostate Cancer: A Systematic Literature Review and Meta-analysis. Eur Urol 2013;63:1040-8.

45. von Eyben FE, Kairemo K. Meta-analysis of 11C-choline and $18 \mathrm{~F}$-choline PET/CT for management of patients with prostate cancer. Nucl Med Commun 2014;35:221-30.

46. Fanti S, Minozzi S, Castellucci P, et al. PET/CT with $11 \mathrm{C}$-choline for evaluation of prostate cancer patients with biochemical recurrence: meta-analysis and critical review of available data. Eur J Nucl Med Mol Imaging 2016;43:55-69.

47. Perera M, Papa N, Christidis D, et al. Sensitivity, Specificity, and Predictors of Positive 68Ga-Prostatespecific Membrane Antigen Positron Emission Tomography in Advanced Prostate Cancer: A Systematic Review and Meta-analysis. Eur Urol 2016;70:926-37.

48. Sawicki LM, Kirchner J, Buddensieck C, et al. Prospective comparison of whole-body MRI and 68 Ga-PSMA PET/ CT for the detection of biochemical recurrence of prostate cancer after radical prostatectomy. Eur J Nucl Med Mol Imaging 2019;46:1542-50.

49. Udovicich C, Perera M, Hofman MS, et al. 68Gaprostate-specific membrane antigen-positron emission tomography/computed tomography in advanced prostate cancer: Current state and future trends. Prostate Int 2017;5:125-9.

50. Lecouvet FE, El Mouedden J, Collette L, et al. Can Whole-body Magnetic Resonance Imaging with Diffusionweighted Imaging Replace Tc 99m Bone Scanning and Computed Tomography for Single-step Detection of Metastases in Patients with High-risk Prostate Cancer? Eur Urol 2012;62:68-75.

51. Perez-Lopez R, Mateo J, Mossop H, et al. Diffusionweighted imaging as a treatment response biomarker for evaluating bone metastases in prostate cancer: A pilot study. Radiology 2017;283:168-77. 
52. Blackledge MD, Collins DJ, Tunariu N, et al. Assessment of treatment response by total tumor volume and global apparent diffusion coefficient using diffusion-weighted MRI in patients with metastatic bone disease: A feasibility study. PLoS One 2014;9:e91779.

53. Jadvar H. Molecular imaging of prostate cancer with PET. J Nucl Med 2013;54:1685-8.

54. Umbehr MH, Müntener M, Hany T, et al. The Role of 11C-Choline and 18F-Fluorocholine Positron Emission Tomography (PET) and PET/CT in Prostate Cancer: A Systematic Review and Meta-analysis. Eur Urol 2013;64:106-17.

55. Songmen S, Nepal P, Olsavsky T, et al. Axumin Positron Emission Tomography: Novel Agent for Prostate Cancer Biochemical Recurrence. J Clin Imaging Sci 2019;9:49.

56. Schuster DM, Nieh PT, Jani AB, et al. Anti-3-[(18)F] FACBC positron emission tomography-computerized tomography and (111)In-capromab pendetide single photon emission computerized tomography-computerized tomography for recurrent prostate carcinoma: results of a prospective clinical trial. J Urol 2014;191:1446-53.

57. von Eyben FE, Picchio M, von Eyben R, et al. 68 GaLabeled Prostate-specific Membrane Antigen Ligand Positron Emission Tomography/Computed Tomography for Prostate Cancer: A Systematic Review and Metaanalysis. Eur Urol Focus 2018;4:686-93.

58. Gupta SK, Watson T, Denham J, et al. Prostate-Specific Membrane Antigen Positron Emission TomographyComputed Tomography for Prostate Cancer: Distribution of Disease and Implications for Radiation Therapy Planning. Int J Radiat Oncol Biol Phys 2017;99:701-9.

59. Padhani AR, Lecouvet FE, Tunariu N, et al. METastasis Reporting and Data System for Prostate Cancer: Practical Guidelines for Acquisition, Interpretation, and Reporting of Whole-body Magnetic Resonance Imaging-based Evaluations of Multiorgan Involvement in Advanced Prostate Cancer. Eur Urol 2017;71:81-92.

60. Kunath F, Borgmann H, Blümle A, et al. Gonadotropinreleasing hormone antagonists versus standard androgen suppression therapy for advanced prostate cancer A systematic review with meta-analysis. BMJ Open 2015;5:e008217.

61. Kyriakopoulos CE, Chen YH, Carducci MA, et al. Chemohormonal Therapy in Metastatic HormoneSensitive Prostate Cancer: Long-Term Survival Analysis of the Randomized Phase III E3805 CHAARTED Trial. J Clin Oncol 2018;36:1080-7.

62. Sweeney CJ, Chen YH, Carducci M, et al.
Chemohormonal therapy in metastatic hormone-sensitive prostate cancer. N Engl J Med 2015;373:737-46.

63. James ND, Sydes MR, Clarke NW, et al. Addition of docetaxel, zoledronic acid, or both to first-line longterm hormone therapy in prostate cancer (STAMPEDE): Survival results from an adaptive, multiarm, multistage, platform randomised controlled trial. Lancet 2016;387:1163-77.

64. James ND, De Bono JS, Spears MR, et al. Abiraterone for prostate cancer not previously treated with hormone therapy. N Engl J Med 2017;377:338-51.

65. Fizazi K, Tran NP, Fein L, et al. Abiraterone plus prednisone in metastatic, castration-sensitive prostate cancer. N Engl J Med 2017;377:352-60.

66. Davis ID, Martin AJ, Stockler MR, et al. Enzalutamide with standard first-line therapy in metastatic prostate cancer. N Engl J Med 2019;381:121-31.

67. Chi KN, Agarwal N, Bjartell A, et al. Apalutamide for metastatic, castration-sensitive prostate cancer. N Engl J Med 2019;381:13-24.

68. Hoyle AP, Ali A, James ND, et al. Abiraterone in "High" and "Low-risk" Metastatic Hormone-sensitive Prostate Cancer(Figure presented.). Eur Urol 2019;76:719-28.

69. Parker CC, James ND, Brawley CD, et al. Radiotherapy to the primary tumour for newly diagnosed, metastatic prostate cancer (STAMPEDE): a randomised controlled phase 3 trial. Lancet 2018;392:2353-66.

70. Boevé LMS, Hulshof MCCM, Vis AN, et al. Effect on Survival of Androgen Deprivation Therapy Alone Compared to Androgen Deprivation Therapy Combined with Concurrent Radiation Therapy to the Prostate in Patients with Primary Bone Metastatic Prostate Cancer in a Prospective Randomised Clinical Tria. Eur Urol 2019;75:410-8.

71. Burdett S, Boevé LM, Ingleby FC, et al. Prostate Radiotherapy for Metastatic Hormone-sensitive Prostate Cancer: A STOPCAP Systematic Review and Metaanalysis. Eur Urol 2019;76:115-24.

72. James ND. Oligometastatic Prostate Cancer Should Be Studied and Treated Differently to High-volume Disease. Con: The Underlying Biology is the Same, So They Should Not Be Treated Differently. Eur Urol Focus 2019;5:119-22.

73. Pastorino U, Buyse M, Friedel G, et al. Long-term results of lung metastasectomy: Prognostic analyses based on 5206 cases. J Thorac Cardiovasc Surg 1997;113:37-49.

74. Fong Y, Cohen AM, Fortner JG, et al. Liver resection for colorectal metastases. J Clin Oncol 1997;15:938-46. 
75. Scheele J, Stang R, Altendorf-Hofmann A, et al. Resection of colorectal liver metastases. World J Surg 1995;19:59-71.

76. Brand DH, Yarnold JR. The Linear-Quadratic Model and Implications for Fractionation. Clin Oncol (R Coll Radiol) 2019;31:673-7.

77. Vogelius IR, Bentzen SM. Dose Response and Fractionation Sensitivity of Prostate Cancer After External Beam Radiation Therapy: A Meta-analysis of Randomized Trials. Int J Radiat Oncol Biol Phys 2018;100:858-65.

78. Hegemann NS, Guckenberger M, Belka C, et al. Hypofractionated radiotherapy for prostate cancer. Radiat Oncol 2014;9:275.

79. Brown JM, Carlson DJ, Brenner DJ. The tumor radiobiology of SRS and SBRT: Are more than the 5 Rs involved? Int J Radiat Oncol Biol Phys 2014;88:254-62.

80. Sutera P, Clump DA, Kalash R, et al. Initial Results of a Multicenter Phase 2 Trial of Stereotactic Ablative Radiation Therapy for Oligometastatic Cancer. Int J Radiat Oncol Biol Phys 2019;103:116-22.

81. Ost P, Reynders D, Decaestecker K, et al. Surveillance or metastasis-directed therapy for oligometastatic prostate cancer recurrence: A prospective, randomized, multicenter phase II trial. J Clin Oncol 2018;36:446-53.

82. Phillips R, Shi WY, Deek M, et al. Outcomes of Observation vs Stereotactic Ablative Radiation for Oligometastatic Prostate Cancer: The ORIOLE Phase 2 Randomized Clinical Trial. JAMA Oncol 2020;6:650-9.

83. Ost P. It Ain't Over Till the Fat Lady Sings: The POPSTAR Trial. Eur Urol 2018;74:463-4.

84. Decaestecker K, De Meerleer G, Lambert B, et al. Repeated stereotactic body radiotherapy for oligometastatic prostate cancer recurrence. Radiat Oncol 2014;9:135.

85. Bouman-Wammes EW, van Dodewaard-De Jong JM, Dahele M, et al. Benefits of Using Stereotactic Body Radiotherapy in Patients With Metachronous Oligometastases of Hormone-Sensitive Prostate Cancer Detected by $[18 \mathrm{~F}]$ fluoromethylcholine PET/CT. Clin Genitourin Cancer 2017;15:e773-82.

86. Ost P, Jereczek-Fossa BA, As NV, et al. Progressionfree Survival Following Stereotactic Body Radiotherapy for Oligometastatic Prostate Cancer Treatment-naive Recurrence: A Multi-institutional Analysis. Eur Urol 2016;69:9-12.

87. Vilela RA, Navarro NF, Faria ET, et al. Use of stereotactic body radiation therapy for oligometastatic recurrent prostate cancer: A systematic review. J Med Imaging Radiat Oncol 2018;62:692-706.
88. Zaorsky NG, Palmer JD, Hurwitz MD, et al. What is the ideal radiotherapy dose to treat prostate cancer? A meta-analysis of biologically equivalent dose escalation. Radiother Oncol 2015;115:295-300.

89. Dunne EM, Sahgal A, Lo SS, et al. International consensus recommendations for target volume delineation specific to sacral metastases and spinal stereotactic body radiation therapy (SBRT). Radiother Oncol 2020;145:21-9.

90. Lewis SL, Porceddu S, Nakamura N, et al. Definitive Stereotactic Body Radiotherapy (SBRT) for Extracranial Oligometastases: An International Survey of $>1000$ Radiation Oncologists. Am J Clin Oncol 2017;40:418-22.

91. Murphy DG, Sweeney CJ, Tombal B. "Gotta Catch 'em All", or Do We? Pokemet Approach to Metastatic Prostate Cancer. Eur Urol 2017;72:1-3.

92. Tree AC, Siva S, Ost P. Re: Declan G. Murphy, Christopher J. Sweeney, Bertrand Tombal. "Gotta Catch 'em All" or Do We? Pokemet Approach to Metastatic Prostate Cancer. Eur Urol 2017;72:1-3. Eur Urol 2017;72:e66-7.

93. Miyahira AK, Roychowdhury S, Goswami S, et al. Beyond Seed and Soil: Understanding and Targeting Metastatic Prostate Cancer; Report From the 2016 Coffey-Holden Prostate Cancer Academy Meeting. Prostate 2017;77:123-44.

94. De Bleser E, Jereczek-Fossa BA, Pasquier D, et al. Metastasis-directed Therapy in Treating Nodal Oligorecurrent Prostate Cancer: A Multi-institutional Analysis Comparing the Outcome and Toxicity of Stereotactic Body Radiotherapy and Elective Nodal Radiotherapy. Eur Urol 2019;76:732-9.

95. PEACE V: Salvage Treatment of OligoRecurrent Nodal Prostate Cancer Metastases [Internet]. [cited 2020 May 24]. Available online: https://clinicaltrials.gov/ct2/show/ NCT03569241 ?term=03569241\&draw=2\&rank=1

96. Conventional Care Versus Radioablation (Stereotactic Body Radiotherapy) for Extracranial Oligometastases [Internet]. [cited 2020 May 24]. Available online: https:// clinicaltrials.gov/ct2/show/NCT02759783? term $=0275978$ $3 \&$ draw $=2 \&$ rank $=1$

97. Stereotactic Ablative Radiotherapy for Comprehensive Treatment of Oligometastatic (1-3 Metastases) Cancer [Internet]. [cited 2020 May 24]. Available online: https:// clinicaltrials.gov/ct2/show/NCT03862911? term=0386291 $1 \&$ draw $=2 \&$ rank $=1$

98. Stereotactic Ablative Radiotherapy for Comprehensive Treatment of 4-10 Oligometastatic Tumors [Internet]. [cited 2020 May 24]. Available online: https://clinicaltrials. gov/ct2/show/NCT03721341? term=03721341\&draw=2\& 
rank $=1$

99. Phase II Randomized Trial of Radiation Therapy in Oligometastatic mCRPC Prostate Cancer (ARTO) [Internet]. [cited 2020 May 24]. Available online: https:// clinicaltrials.gov/ct2/show/NCT03449719?term=0344971 9\&draw $=2 \&$ rank $=1$

100. Prostate-cancer Treatment Using Stereotactic Radiotherapy for Oligometastases Ablation in Hormonesensitive Patients [Internet]. [cited 2020 May 24]. Available online: https://clinicaltrials.gov/ct2/show/NCT04115007

101.Local Ablative Therapy For Hormone Sensitive Oligometastatic Prostate Cancer [Internet]. [cited 2020 May 24]. Available online: https://clinicaltrials.gov/ct2/ show/NCT03784755 ?term=03784755\&draw=2\&rank=1

102. Systemic and Tumor-Directed Therapy for Oligometastatic Prostate Cancer [Internet]. [cited 2020 May 25]. Available online: https://clinicaltrials.gov/ct2/ show/NCT03298087

103. A Study of Definitive Therapy to Treat Prostate Cancer [Internet]. [cited 2020 May 25]. Available online: https:// clinicaltrials.gov/ct2/show/NCT02716974?term=john+hop kins $\% 2 \mathrm{C}+$ pienta\&cond=Prostate + Cancer $\&$ draw $=2 \&$ rank $=5$ 104. Van den Broeck T, van den Bergh RCN, Arfi N, et al. Prognostic Value of Biochemical Recurrence Following Treatment with Curative Intent for Prostate Cancer: A Systematic Review. Eur Urol 2019;75:967-87.

105. Duchesne GM, Woo HH, Bassett JK, et al. Timing of androgen-deprivation therapy in patients with prostate cancer with a rising PSA (TROG 03.06 and VCOG PR 01-03 [TOAD]): a randomised, multicentre, non-blinded, phase 3 trial. Lancet Oncol 2016;17:727-37.

106. Studer UE, Whelan P, Albrecht W, et al. Immediate or Deferred Androgen Deprivation for Patients With Prostate Cancer Not Suitable for Local Treatment With Curative Intent: European Organisation for Research and Treatment of Cancer (EORTC) Trial 30891. J Clin Oncol 2006;24:1868-76.

107. Moul JW, Wu H, Sun L, et al. Early Versus Delayed Hormonal Therapy for Prostate Specific Antigen Only Recurrence of Prostate Cancer After Radical Prostatectomy. J Urol 2008;179:S53-9.

108. Alfred Witjes J, Lebret T, Comperat EM, et al. Updated 2016 EAU Guidelines on Muscle-invasive and Metastatic Bladder Cancer. Eur Urol 2017;71:462-75.

109.Hussain M, Tangen CM, Berry DL, et al. Intermittent versus Continuous Androgen Deprivation in Prostate Cancer. N Engl J Med 2013;368:1314-25.

110.Hussain M, Tangen C, Higano C, et al. Evaluating
Intermittent Androgen-Deprivation Therapy Phase III Clinical Trials: The Devil Is in the Details. J Clin Oncol 2016;34:280-5.

111. Pollack A, Karrison TG, Balogh AG, et al. Short Term Androgen Deprivation Therapy Without or With Pelvic Lymph Node Treatment Added to Prostate Bed Only Salvage Radiotherapy: The NRG Oncology/RTOG 0534 SPPORT Trial. Int J Radiat Oncol 2018;102:1605.

112.Shipley WU, Seiferheld W, Lukka HR, et al. Radiation with or without antiandrogen therapy in recurrent prostate cancer. N Engl J Med 2017;376:417-28.

113. Bolla M, Maingon P, Carrie C, et al. Short androgen suppression and radiation dose escalation for intermediateand high-risk localized prostate cancer: Results of EORTC trial 22991. J Clin Oncol 2016;34:1748-56.

114. Spina CS. Androgen deprivation therapy and radiation therapy for prostate cancer: The mechanism underlying therapeutic synergy. Transl Cancer Res 2018;7:S695-703.

115. Chaw CL, DeSouza NM, Khoo V, et al. Clinical Outcomes of Stereotactic Body Radiotherapy With Immediate Versus Delayed Hormone Therapy in Men With Oligometastatic Recurrence of Prostate Cancer. Clin Oncol (R Coll Radiol) 2020;32:509-17.

116. Palma DA, Olson R, Harrow S, et al. Stereotactic ablative radiotherapy versus standard of care palliative treatment in patients with oligometastatic cancers (SABRCOMET): a randomised, phase 2, open-label trial. Lancet 2019;393:2051-8.

117. Soloway MS, Hardeman SW, Hickey D, et al. Stratification of patients with metastatic prostate cancer based on extent of disease on initial bone scan. Cancer 1988;61:195-202.

118. O’Shaughnessy MJ, McBride SM, Vargas HA, et al. A Pilot Study of a Multimodal Treatment Paradigm to Accelerate Drug Evaluations in Early-stage Metastatic Prostate Cancer. Urology 2017;102:164-72.

119. Tabata K, Niibe Y, Satoh T, et al. Radiotherapy for oligometastases and oligo-recurrence of bone in prostate cancer. Pulm Med 2012;2012:541656.

120. Tsumura H, Ishiyama H, Tabata KI, et al. Long-term outcomes of combining prostate brachytherapy and metastasis-directed radiotherapy in newly diagnosed oligometastatic prostate cancer: A retrospective cohort study. Prostate 2019;79:506-14.

121.Deek MP, Tran PT. Oligometastatic and Oligoprogression Disease and Local Therapies in Prostate Cancer. Cancer J 2020;26:137-43.

122. Oligometastatic cancer: Total Eradication of Disease (TED) Trials - Kenneth J. Pienta [Internet]. [cited 2020 
May 25]. Available online: https://www.kennethjpienta. com/new-page

123. Ventimiglia E, Seisen T, Abdollah F, et al. A Systematic Review of the Role of Definitive Local Treatment in Patients with Clinically Lymph Node-positive Prostate Cancer. Eur Urol Oncol 2019;2:294-301.

124. James ND, Spears MR, Clarke NW, et al. Failure-free survival and radiotherapy in patients with newly diagnosed nonmetastatic prostate cancer. JAMA Oncol 2016;2:348-57.

125. Triggiani L, Mazzola R, Magrini SM, et al. Metastasisdirected stereotactic radiotherapy for oligoprogressive castration-resistant prostate cancer: a multicenter study. World J Urol 2019;37:2631-7.

126. Targeted Radiotherapy in Androgen-suppressed Prostate
Cancer Patients. [Internet]. [cited 2020 May 25]. Available online: https://clinicaltrials.gov/ct2/show/NCT03644303

127. Chang DT, Pollom EL, Keane FK, et al. Treating Oligometastatic Disease With SABR: More Than Just a Numbers Game? Int J Radiat Oncol Biol Phys 2020;107:257-60.

128. Prostate Cancer With OligometaSTatic Relapse: Combining Stereotactic Ablative Radiotherapy and Durvalumab (MEDI4736) [Internet]. [cited 2020 May 24]. Available online: https://clinicaltrials.gov/ct2/show/NCT0 3795207 ?term $=03795207 \&$ draw $=2 \&$ rank $=1$

129. Palma DA, Bauman GS, Rodrigues GB. Beyond Oligometastases. Int J Radiat Oncol Biol Phys 2020;107:253-6.
Cite this article as: Sritharan $\mathrm{K}$, Rieu $\mathrm{R}$, Tree A. A narrative review of oligometastatic prostate cancer-an evolving paradigm. Ann Palliat Med 2021;10(5):5969-5987. doi: 10.21037/ apm-20-1215 